\title{
Myocarditis Induced by Immune Checkpoint Inhibitors: Mechanisms and Therapeutic Prospects
}

\author{
Wenlu Zou ${ }^{1-3, *}$ \\ Jie $\mathrm{Lu}^{4, *}$ \\ Yan $\mathrm{HaO}^{5}$ \\ 'Department of Gastroenterology, \\ Shandong Provincial Hospital Affiliated to \\ Shandong First Medical University, Jinan, \\ Shandong Province, 25002I, People's \\ Republic of China; ${ }^{2}$ Department of \\ Infectious Disease, ${ }^{3}$ Department of \\ Clinical Laboratory, Shandong University \\ Qilu Hospital, Jinan, Shandong Province, \\ 2500 I2, People's Republic of China; \\ ${ }^{4}$ Department of Neurosurgery, The First \\ Affiliated Hospital of Shandong First \\ Medical University \& Shandong Provincial \\ Qianfoshan Hospital, Shandong Medicine \\ and Health Key Laboratory of \\ Neurosurgery, Jinan, 250II7, Shandong \\ Province, People's Republic of China; \\ ${ }^{5}$ Department of Cardiology, Shandong \\ Provincial Hospital Affiliated to Shandong \\ First Medical University, Jinan, 25002I, \\ Shandong Province, People's Republic of \\ China
}

*These authors contributed equally to this work
Correspondence: Yan Hao Email haoyan02_09@sina.com

\begin{abstract}
Under physiological conditions, immune checkpoint molecules downregulate the activation and effector function of myocardial antigen-reactive T cells through an immunosuppressive pathway, thus enabling myocardial $\mathrm{T}$ cells to maintain immune homeostasis under the action of central and peripheral tolerance mechanisms. The PD-1/PD-L1 signalling pathway is particularly important for limiting the ability of $\mathrm{T}$ cells to attack the heart. Immune checkpoint inhibitors (ICIs) specifically block this PD-1/PD-L1-mediated restriction of $\mathrm{T}$ cell activation and other immunosuppressive pathways by targeting immune checkpoints. In recent years, with the wide use of ICIs in cancer treatment, even though the incidence of immunomyocarditis is low, it has attracted increasing attention because of its complex clinical symptoms, rapid progression of disease and high mortality rates. The pathogenesis, genetic susceptibility factors and predictive biomarkers of immunomyocarditis still need to be understood, and multidisciplinary cooperation in the clinical treatment of this complication is necessary.
\end{abstract}

Keywords: immunomyocarditis, immune checkpoint inhibitors, anti-PD-1/PD-L1, cancer

\section{Introduction}

Remarkable clinical efficacy has been achieved with programmed death 1 (PD-1), programmed death ligand-1 (PD-L1), and cytotoxic T-lymphocyte associated protein-4 (CTLA-4) blockades and these treatments have survival benefits when applied to treat several cancers, including head and neck squamous cell carcinoma, urothelial cancer, Hodgkin's lymphoma, non-Hodgkin's lymphoma, gastric cancer, adenocarcinoma of the gastroesophageal junction, liver cancer, colorectal cancer, Merkel cell carcinoma, triple negative breast cancer, and squamous cell carcinoma. ${ }^{1-10}$ Since the first ICI targeting CTLA-4 (ipilimumab) was approved as a post-first-line treatment for unresectable or metastatic melanoma by the FDA in $2011,{ }^{11}$ the FDA has approved seven ICIs, comprising anti-PD-1 (pembrolizumab, nivolumab), anti-PD-L1 (atezolizumab, durvalumab, avelumab), and anti-CTLA-4 (ipilimumab, tremelimumab) drugs.

Due to the clonality between normal tissues or organs and tumour cell surface antigens, although ICIs can restore the tumour-killing function of cytotoxic T cells, ICIs inevitably attenuate the self-tolerance of the body to autoimmune cells and lead to multiple systemic immune-related adverse events (irAEs). The related irAEs reported in studies include rash, colitis, pneumonitis, hepatitis, neurologic, nephritis, haematologic, infection, thrombosis, electrolyte imbalance, and multiorgan failure. ${ }^{12,13}$ Immunomyocarditis is characterized by hidden symptoms and a high 
mortality rate. Therefore, though immunomyocarditis is rare, this ICI-mediated side effect is important to consider in clinical work. ${ }^{14}$ The incidence of immunomyocarditis was $0.06-1 \%$ in cancer patients enrolled in clinical trials receiving ICIs. ${ }^{15}$ Furthermore, Johnson et al demonstrated a significant difference in the immunomyocarditis incidence rate between patients treated with nivolumab $(0.06 \%)$ and those treated with nivolumab plus ipilimumab $(0.27 \%){ }^{16}$

Immunomyocarditis commonly presents as heart failure, arrhythmia, myocardial pericarditis, cardiomyopathy, myocardial fibrosis, cardiogenic shock, and cardiogenic death. ${ }^{17-21}$ The lack of specific symptoms in the early stage of immunomyocarditis and the lack of regular cardiovascular examinations in the course of disease management lead to the underestimation of the incidence of immunomyocarditis and the severity of the disease. At present, no guidelines exist for the diagnosis and treatment of immunomyocarditis. ${ }^{15}$

In this review, we analyse the mechanism and breakthroughs of ICIs in the treatment of tumours, the pathogenesis of immunomyocarditis, the potential risk factors for immunomyocarditis, the consensus of diagnosis and management of immunomyocarditis, and the exploration of treatment models that may reduce the risk of immunomyocarditis.

\section{Immune Checkpoint Inhibitors in Cancers \\ CTLA-4 and PD-I/PD-LI}

Breakthroughs have been made in clinical trials that evaluated ICIs that specifically block the CTLA-4 and PD-1/ PD-L1 signalling; thus, these were the first immunotherapy drugs to be used for cancer.

CTLA-4 is a transmembrane receptor expressed on $\mathrm{T}$ cells and shares B7 molecular ligands with CD28. The competitive binding of CTLA-4 molecule on the $\mathrm{T}$ cell surface to the B7 molecule on APC cell surfaces leads to the activation of negative costimulatory molecules, which in turn inhibits the activation of $\mathrm{T}$ cells (Figure 1). ${ }^{22-26}$ PD-L1 is mainly expressed on the surface of a variety of solid tumour cells. ${ }^{27-33}$ The PD-1/PD-L1 signal pathway is formed by PD-1, which is highly expressed on T cell surface, and the PD-L1 or PD-L2 molecule, which is expressed on the tumour cell surface and transmits inhibitory signal to effector $\mathrm{T}$ cells, inhibits $\mathrm{T}$ cell proliferation and specific killing of tumour cells, and allows tumour cells to escape the immune system. ${ }^{34-36}$

The FDA has approved two kinds of ICIs blocking the CTLA-4/B7 pathway, which include anti-CTLA-4 drugs (ipilimumab, tremelimumab) (Table 1). Ipilimumab is the first drug in history to significantly improve the OS rate of patients with advanced metastatic melanoma. According to

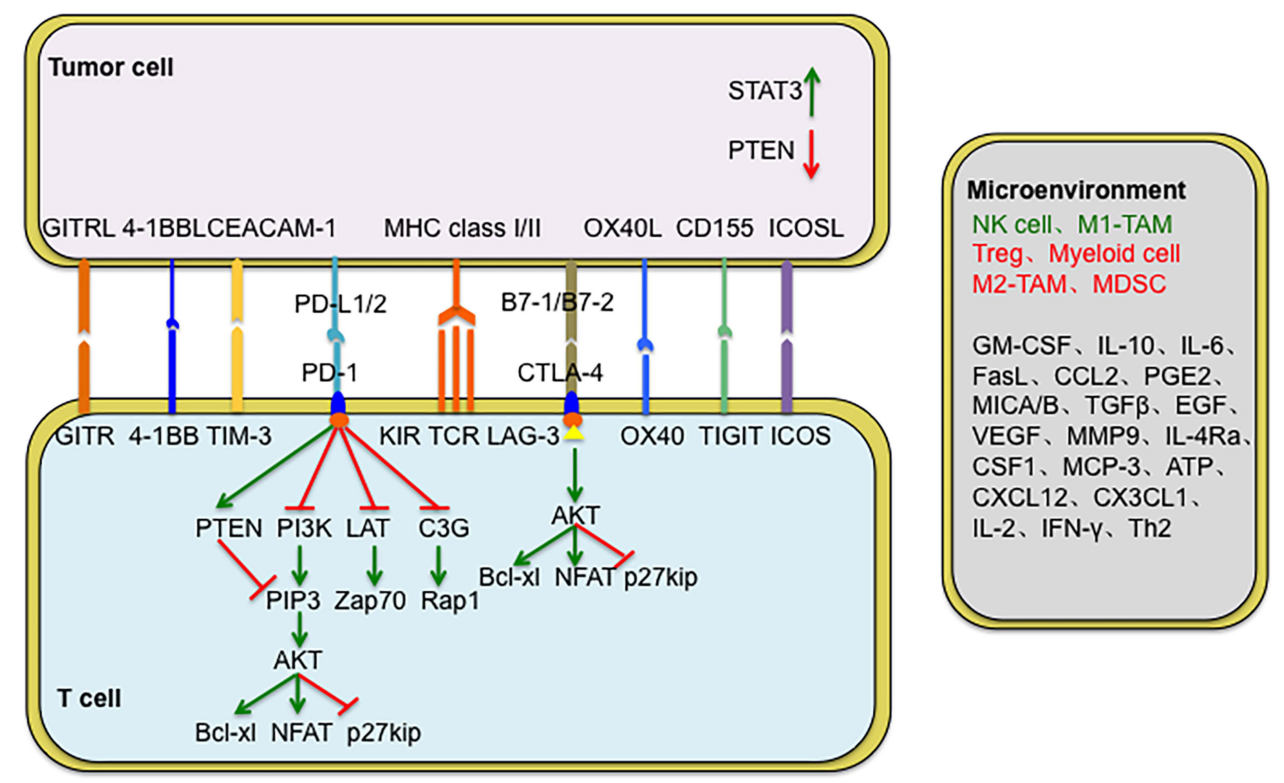

Figure I Mechanism of PD-I and CTLA-4 in inhibiting T cell activation.

Abbreviations: TIM-3, T cell immunoglobulin domain and mucin domain-3; LAG-3, Lymphocyte activation gene-3; TCR, T cell receptor; TIGIT, T cell immunoreceptor with Ig and ITIM domains; AKT, protein kinase; Bcl-xl, B cell lymphoma xl; ZAP70, zeta-chain-associated protein kinase 70. 
Table I FDA-Approved 7 Kinds of Immune Checkpoint Inhibitors

\begin{tabular}{|c|c|c|c|c|c|}
\hline $\begin{array}{l}\text { Target } \\
\text { Pathway }\end{array}$ & Agent & IgG Class & Company & Approved Cancer & References \\
\hline \multirow[t]{2}{*}{ CTLA-4 } & Ipilimumab & Human $\operatorname{lgGI}$ & Bristol-Meyers Squibb & Melanoma & [37] \\
\hline & Tremelimumab & Human $\operatorname{lgG} 2$ & AstraZeneca & Malignant mesothelioma & [38] \\
\hline \multirow[t]{2}{*}{ PD-I } & Pembrolizumab & Humanized lgG4 & Merck & $\begin{array}{l}\text { Melanoma } \\
\text { Lung cancer } \\
\text { Head and neck cancer }\end{array}$ & $\begin{array}{l}{[39]} \\
{[40,41]} \\
{[42]}\end{array}$ \\
\hline & Nivolumab & Human IgG4 & $\begin{array}{l}\text { Bristol-Meyers Squibb/Ono } \\
\text { Colorectal cancer }\end{array}$ & $\begin{array}{l}\text { Melanoma } \\
\text { Non-small cell lung cancer } \\
\text { Kidney cancer } \\
\text { Hodgkin's lymphoma } \\
\text { Squamous cell carcinoma of the head and } \\
\text { neck } \\
\text { Urothelial carcinoma } \\
\text { Hepatocellular carcinoma }\end{array}$ & $\begin{array}{l}{[11]} \\
{[43,44]} \\
{[45]} \\
{[46]} \\
{[47]} \\
{[48]} \\
{[49]}\end{array}$ \\
\hline \multirow[t]{3}{*}{ PD-LI } & Atezolizumab & Humanized lgGIk & Roche/Genentech & $\begin{array}{l}\text { Urothelial cancer } \\
\text { Non-small cell lung cancer }\end{array}$ & $\begin{array}{l}{[50]} \\
{[51]}\end{array}$ \\
\hline & Durvalumab & Human lgGIk & Medimmune/AstraZeneca & $\begin{array}{l}\text { Urothelial cancer } \\
\text { Non-small cell lung cancer } \\
\text { Small cell lung cancer }\end{array}$ & $\begin{array}{l}{[53]} \\
{[54]} \\
{[55]}\end{array}$ \\
\hline & Avelumab & Human IgGI & Merck Serono/Pfizer & $\begin{array}{l}\text { Meckel cell carcinoma } \\
\text { Urothelial cancer }\end{array}$ & $\begin{array}{l}{[56]} \\
{[57]}\end{array}$ \\
\hline
\end{tabular}

the results of the DETERMINE clinical trial, tremelimumab has been approved as a second-line or third-line treatment for relapsed malignant mesothelioma. ${ }^{38}$

The FDA has approved five kinds of ICIs blocking the PD-1/PD-L1 pathway, which include anti-PD-1 (pembrolizumab, nivolumab) and anti-PD-L1 (atezolizumab, durvalumab, avelumab) drugs (Table 1). Pembrolizumab has been approved as a first-line treatment for advanced nonsmall cell lung cancer (NSCLC) positive for PD-L1 expression (>50\%) (Keynote-024). ${ }^{40,41}$ Nivolumab has been approved as a second-line treatment for advanced squamous NSCLC (CheckMate-017) and advanced nonsquamous NSCLC (CheckMate-057). ${ }^{43,44}$ According to the results of the POPLAR and OAK clinical trials, atezolizumab has been approved as a second-line treatment for advanced NSCLC. ${ }^{5,51,52}$ Durvalumab was approved as the standard treatment for locally advanced or metastatic urothelial cancer in $2017 . .^{53}$ Subsequently, avelumab has been approved for the treatment of metastatic Merkel cell carcinoma. $^{56}$ Additionally, combining anti-PD-1/PD-L1 and anti-CTLA-4 antibodies could further strengthen the antitumour efficacy of the drugs and patient survival outcomes. $^{58-60}$

\section{Other Targets}

Recently, many studies have proposed that other immune checkpoint molecules also play an important role in tumour progression, but they are still in the research stage, and there are no drugs approved by the FDA for clinical treatment at present.

\section{TIM-3}

Similar to PD-1 and CTLA-4, T cell immunoglobulin domain and mucin domain-3 (TIM-3) is also an inhibitory receptor expressed on the surface of CD4+ $\mathrm{T}$ helper 1 and $\mathrm{CD} 8+$ $\mathrm{T}$ cytotoxic cells that results in $\mathrm{T}$ cell exhaustion. ${ }^{61-63}$ Sakuishi et al found that CD8 + T cells exhibited an exhaustion status with a PD-1+/TIM3+ phenotype and that anti-TIM-3 could reverse the therapy resistance induced by anti-PD- $1 .{ }^{64}$

\section{LAG-3}

Lymphocyte activation gene-3 (LAG-3) is another immune checkpoint inhibitor that is expressed on the surface of T cells, B cells, NK cells, and DCs. LAG-3 could inhibit the killing efficacy of $\mathrm{T}$ cells and promote the intrinsic inhibitory function of Tregs. ${ }^{65}$ Anti-LAG-3 synergises 
with anti-PD-1 and can restore CD8+ T cell function and reduce tumour immune escape. ${ }^{66,67}$

\section{TIGIT}

$\mathrm{T}$ cell immunoreceptors with Ig and ITIM domains (TIGIT) are widely expressed on human tumourinfiltrating T cells. TIGIT synergises with inhibitory receptors such as PD-1, TIM-3, and LAG-3, and leads to exhaustion of infiltrating $\mathrm{T}$ cells and weakens the tumour killing ability of cytotoxic CD8 $+\mathrm{T}$ cells. Robert et al demonstrated that co-blockade of TIGIT and PD-L1 significantly enhanced CD8 $+\mathrm{T}$ cell function and reduced tumour volume. ${ }^{68}$

\section{Inhibitory Pathways in Myocardial Immune Homeostasis}

PD-1, a receptor of the IgM superfamily, is an immunosuppressive receptor that is usually expressed on the surface of activated $\mathrm{T}$ cells, B cells and myeloid cells. It negatively regulates the signal transduction of $T$ cell antigen receptors by interacting with the specific ligand PD-L1 and is thought to play a role in maintaining self-tolerance in the immune system. ${ }^{69}$ PD-L1 is expressed by antigenpresenting cells, including peripheral blood monocytes and activated dendritic cells. ${ }^{70}$ In 1998, to analyze the role of PD-1 molecules in the immune response, Nishimura et al selected PD-1 gene-deficient mice as experimental subjects. The results showed that PD-1 signalling molecules inhibit the proliferation and differentiation of B lymphocytes. Similar to CTLA-4 signalling molecules, PD-1 molecules also weaken the immune response. ${ }^{71}$ In addition, Freeman et al found that the expression level of PD-L1 mRNA in mouse heart tissue was very high. ${ }^{70}$ Rodig et al confirmed that IFN- $\gamma$ could induce mouse cardiac endothelial cells cultured in vitro to express PDL1, and that this significantly weakened the IFN- $\gamma$ mediated class I MHC restriction antigen presentation to cytotoxic $T$ lymphocytes through the PD-1/PD-L1 signalling pathway. Furthermore, IFN- $\gamma$ could enhance the resistance of mouse cardiac endothelial cells to cytotoxic $\mathrm{T}$ lymphocyte attack and maintain the immune homeostasis of cardiac endothelial cells. ${ }^{72}$ To further confirm the role of PD-L1 in maintaining the immune homeostasis of cardiomyocytes, Grabie et al established a mouse model of cytotoxic T lymphocyte-mediated immunomyocarditis and used PD-L1/L2 gene-deficient mice and PD-L1/L2specific antibodies to study the effect of the PD-L1 signalling pathway on the myocardium. The results showed that blocking PD-L1 could increase the microabscess formed by leukocytes but did not affect the recruitment of cytotoxic $\mathrm{T}$ lymphocytes. This eventually lead to the transformation of immunomyocarditis into fatal heart disease. ${ }^{73}$ The above studies reveal that the PD-L1 signalling pathway plays a role in immune tolerance and myocardial protection mainly by limiting the effect of CTLs rather than by reducing the recruitment of CTLs to cardiomyocytes. Under normal physiological conditions, DCs continuously present cardiac antigens to naïve $\mathrm{T}$ cells in cardiac draining lymph nodes, making the heart tolerant to antigen-specific circulating naïve $\mathrm{T}$ cells. When cardiac infection or peripheral tolerance genetic variation occurs, specific naïve $\mathrm{T}$ cells are activated, differentiated and expanded into effector $\mathrm{T}$ cells. IFN- $\gamma$ produced by both effector $\mathrm{T}$ cells and tissues induces cardiomyocytes to express PD-L1, and the PD-1/PD-L1 signalling pathway cooperates with other regulatory mechanisms to protect the heart from $\mathrm{T}$ cell attack and maintain myocardial immune equilibrium. ${ }^{74,75}$

\section{Mechanisms of Immunomyocarditis Arising as a Consequence of ICI Treatment}

ICIs can relieve the PD-1/PD-L1-mediated inhibition of tumour killing $\mathrm{T}$ cells and other immunosuppressive pathways, enhance the function of T cells, and show a good effect in the treatment of many kinds of cancer. Because cardiomyocytes protect themselves from $\mathrm{T}$ cell attacks and maintain immune tolerance through high expression of PD-L1, it is necessary to avoid immunomyocarditis that arises due to immune tolerance with ICI therapy for cancer as immunomyocarditis is caused by the abnormal activation of $\mathrm{T}$ cells and subsequent damage to cardiomyocytes. ${ }^{16}$

In an animal model study, Waterhouse et al studied CTLA-4 gene-deficient mice and found that infiltrating $\mathrm{T}$ cells were significantly activated and neutrophils and macrophages infiltrated the heart, which eventually led to myocardial fibrosis. One month later, CTLA-4 genedeficient mice died of myocardial infarction. ${ }^{26}$ Nishimura et al found that five weeks after PD-1 knockout, the mice died of severe dilated cardiomyopathy, ventricular systolic dysfunction, and congestive heart failure. ${ }^{76}$ Another study also revealed the role of PD-1 in maintaining myocardial immune tolerance. PD-1 knockout mice showed a severe inflammatory response, increased myocardial injury, and 
significantly increased inflammatory cell infiltration in the myocardium. ${ }^{77}$ In addition, PD-1 knockout mice produce autoantibodies against cardiac myosin, which leads to a significant increase in $\mathrm{CD} 4+\mathrm{T}, \mathrm{CD} 8+\mathrm{T}$ and myeloid cell infiltration in the myocardium and eventually develops into fatal immunomyocarditis. ${ }^{78}$

At present, the mechanism of immunomyocarditis is not clear, and the possible mechanisms are as follows. First, immune checkpoint molecules act as new antigens to stimulate the $\mathrm{T}$ cell response. Studies have shown that the expression of PD-L1 molecules is significantly upregulated not only in a variety of tumour cells but also in normal tissues, including cardiac endothelial cells, ${ }^{79}$ respiratory epithelial cells, ${ }^{80}$ renal epithelial cells, ${ }^{81}$ islet cells ${ }^{82}$ and skeletal muscle cells. ${ }^{83}$ One study revealed that two patients developed fulminant immunomyocarditis after treatment with anti-PD-1 plus anti-CTLA-4. Johnson et al analyzed myocardial tissue from these patients and found that PD-L1 was highly expressed in CD8 + T cells infiltrating the myocardium and damaged cardiomyocytes, but no PD-L1 expression was found in skeletal muscle and tumour tissue. $^{16}$ The mechanism of the upregulation of PD-L1 expression in cardiomyocytes after ICI therapy is not clear. A possible explanation is that PD-L1 activates $\mathrm{T}$ cells as a new antigen, the $\mathrm{T}$ cells cannot directly recognize the antigen, and the TCR on the surface of $\mathrm{T}$ cells recognizes the antigen peptide-MHC molecular complex on the surface of antigen-presenting cells to complete the process of antigen recognition. We can detect the TCRmediated clonal expansion of infiltrating $\mathrm{T}$ cells to determine whether PD-L1 expressed by cardiac endothelial cells can stimulate the $\mathrm{T}$ cell response as a new antigen, which leads to immunomyocarditis. Another possibility is that damaged cardiomyocytes inhibit $\mathrm{T}$ cell function activated by ICIs by upregulating PD-L1 expression, thus avoiding further aggravation of immunomyocarditis.

Second, ICIs enhance the ability of $\mathrm{T}$ cells to recognize and bind antigens. A variety of antigen molecules are expressed in tumour and heart tissues, and cardiac antigens express tissue antigens that are homologous to tumour tissues. $^{84,85}$ For instance, Johnson et al analyzed tumour tissue sections from patients who died from immunomyocarditis and found that the tumour tissue highly expressed muscle-specific antigens (desmin and troponin), which are homologous to myocardial tissue. ${ }^{16}$ Therefore, when $\mathrm{T}$ cells recognize tumour antigens, they can circulate and recognize homologous tissue antigens in the heart and promote cardiac inflammatory infiltration and induce off- target effects and the occurrence of immunomyocarditis. ${ }^{83}$ Johnson et al conducted an immunohistochemical analysis of the tissues of two patients with fulminant immunomyocarditis and found that there were a large number of CD4+ and $\mathrm{CD} 8+\mathrm{T}$ cells infiltrating the myocardium, skeletal muscle and tumour tissues. Researchers sequenced the TCR expressed by infiltrating $T$ cells and found that $\mathrm{T}$ cells were highly clonal and had expanded in these tissues, indicating that $\mathrm{T}$ cells recognize antigens in tumour tissues and off-target tissues after activation by ICIs. This in turn leads to the occurrence of immunomyocarditis. To further clarify the exact $\mathrm{T}$ cell subsets activated by ICIs, Yamaguchi et al analyzed peripheral blood mononuclear cells from patients with multiple myeloma by flow cytometry and found that CD4+ and CD8+ $\mathrm{T}$ cells increased after treatment with ICIs. $^{86}$ In addition, a number of studies have shown that CD4+ and CD8+ $\mathrm{T}$ cells are involved in the pathological process of immunomyocarditis. Th2 cell subsets and Th17 subsets of CD4+ $T$ cells regulate cardiac inflammation by secreting inflammatory mediators and promote the occurrence of immunomyocarditis. ${ }^{87-89} \mathrm{CD} 8+\mathrm{T}$ cells play a cytotoxic role in promoting the occurrence and progression of immunomyocarditis. ${ }^{90,91}$

Third, the infiltration of inflammatory factors into offtarget organs promotes the progression of immunomyocarditis. Recent studies have shown that a patient with recurrent metastatic melanoma developed acute renal interstitial glomerulonephritis after receiving anti-CTLA -4 combined with anti-PD-1 therapy. Through analysis, they found that the levels of serum proinflammatory cytokines, such as IL-1Ra, CXCL10 and TNF- $\alpha$, were significantly increased (Figure 2). ${ }^{16}$ However, there is still a lack of clinical evidence for the function of circulating cytokines in patients with immunomyocarditis. The involvement of inflammatory cytokines in the development of immunomyocarditis needs to be confirmed in further clinical studies.

Autopsy analysis showed that the infiltration of $\mathrm{CD} 3+\mathrm{T}$ cells, CD4+T cells and CD8+T cells in the myocardial tissue of patients with immunomyocarditis was significantly increased. ${ }^{92}$ Professor Hardy found that CD3+T cells and CD68+ macrophages mainly infiltrated into myocardial tissue, while the number of $\mathrm{CD} 4+\mathrm{T}$ cells in the $\mathrm{CD} 3+\mathrm{T}$ cell population was significantly higher than the number of $\mathrm{CD} 8+\mathrm{T}$ cells. ${ }^{93}$ The myocardial biopsy of another melanoma patient treated with Nivo monoclonal antibody showed infiltration of CD8+ and PD-1- T cells. ${ }^{94}$ 


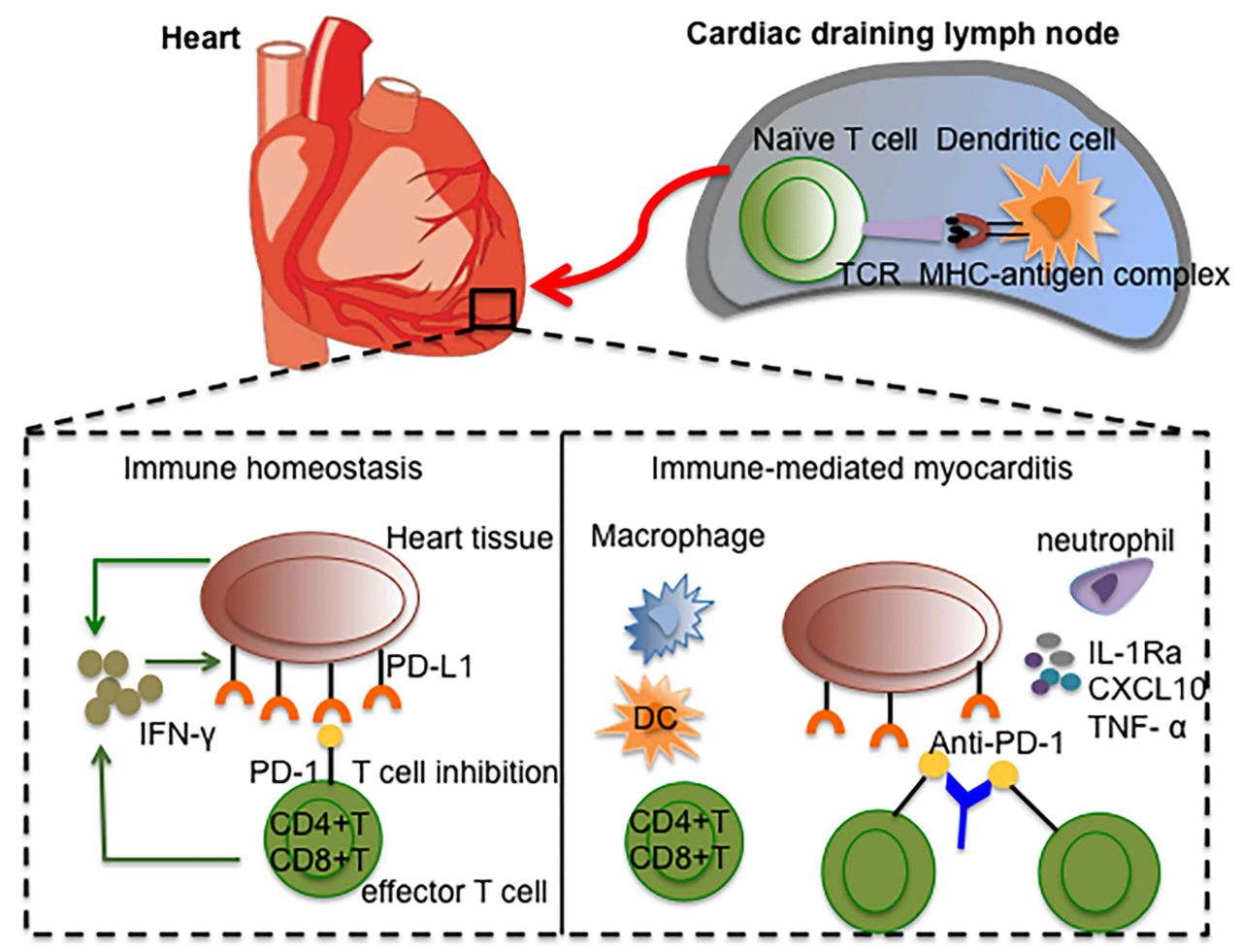

Figure 2 Anti-PD-I therapy breaks the peripheral immune tolerance by unleashing effective $T$ cells.

Abbreviations: DC, dendritic cell; CXCLI0, CXCchemokineligand-10; TNF- $\alpha$, tumor necrosis factor alpha.

Sobol et al analyzed the myocardial biopsy samples of 6 patients with immunomyocarditis and found that most immunomyocarditis was multifocal/diffuse lesions, in which $\mathrm{CD} 8+$ and PD-1+ T cell infiltration was increased, and confirmed the expression of PD-L1-mediated immune activity in the myocardial lesion area. ${ }^{95}$ Champion et al divided 10 patients with immunomyocarditis into two subgroups, high-grade immunomyocarditis $(>50 \mathrm{CD} 3+$ cells/ hpf) and low-grade immunomyocarditis $(\leq 50 \mathrm{CD} 3+$ cells/ hpf). Their study revealed that the density of CD3 $+\mathrm{T}$ cells, CD8+ $\mathrm{T}$ cells and CD68+ macrophages in patients with high-grade immunomyocarditis was higher, the time to disease onset was shorter, the clinical symptoms were more severe, and the survival rate was lower. ${ }^{96}$

\section{Clinical Characteristics and Therapeutic Implications of Immunomyocarditis}

The timing of immunomyocarditis varies. Hardy et al reported an 81-year-old patient with recurrent renal cell carcinoma who developed third-degree heart failure two days after receiving anti-PD-1 combined with anti-CTLA -4 and died of severe immunomyocarditis on the third day. ${ }^{93}$ Some studies have shown that immunomyocarditis is an early cardiotoxicity after treatment with antiPD-1 combined with anti-CTLA-4, and the median time for diagnosis from the first dose of ICI is approximately 15 days, ${ }^{12,16}$ while after the first dose of anti-PD-1 or antiCTLA-4, the median time for diagnosis of immunomyocarditis is 40 days. ${ }^{12}$ In addition, a retrospective study showed that $76 \%$ of immunomyocarditis occurrences arose within 6 weeks after the first dose of ICI, with a median time of 27 days (5-155 days). ${ }^{97}$ Compared with ICI-mediated early immunomyocarditis (occurring in the first 90 days of treatment), ICI-mediated late immunomyocarditis (after the first 90 days of treatment) is more likely to develop heart failure. ${ }^{98}$ Although the incidence of immunomyocarditis is not high, the mortality rate of immunomyocarditis is the highest of all ICI-mediated side effects. Wang et al retrospectively analyzed 613 cases of fatal ICI-mediated side effects reported from 2009 to 2018 and found that 333 cases were caused by anti-PD-1/PD-L1, and 27 patients (8\%) died from immunomyocarditis. In addition, 87 cases were caused by antiPD-1 combined with anti-CTLA-4, and 22 patients died from immunomyocarditis (25\%). ${ }^{15}$ Moslehi et al found that among 101 patients with severe immunomyocarditis, 
the mortality rate of patients treated with anti-PD-1/PD-L1 was $36 \%$, while that of patients treated with anti-PD-1/PDL1 combined with anti-CTLA-4 was as high as $67 \% .{ }^{97}$ In addition, patients with diabetes were more likely to develop immunomyocarditis. Therefore, we should pay considerable attention to the high mortality rate of immunomyocarditis.

Patients with immunomyocarditis have different onset times and various clinical symptoms after receiving ICI treatment. The initial symptoms of low-grade immunomyocarditis lack specificity, and most of them are common uncomfortable symptoms, such as palpitation, fatigue, and chest tightness. On the other hand, high-grade immunomyocarditis usually has serious clinical symptoms such as fulminant immunomyocarditis and a high mortality rate. ${ }^{96}$ Typical clinical symptoms of immunomyocarditis include palpitation, chest pain, fatigue, left ventricular systolic dysfunction, abnormal myocardial zymogram, arrhythmia, heart failure and myocardial infarction. ${ }^{14,16,19-21,99,100}$ For patients with suspected immunomyocarditis during ICI treatment, a cardiologist should be immediately consulted to compare baseline electrocardiogram and echocardiography with immediate electrocardiogram and echocardiography. Furthermore, cardiac biomarkers and inflammatory biomarkers should be dynamically monitored. In clinical practice, baseline electrocardiogram (ECG) and troponin tests are usually performed in patients treated with ICIs. ECG and troponin were measured 7 days after the first injection of ICIs and were also measured before each cycle of ICI treatment. If necessary, cardiac magnetic resonance imaging or myocardial biopsy should be performed to diagnose the condition (Figure 3). ${ }^{101}$ For patients with grade 1 or 2 mild immunomyocarditis, intravenous injection of methylprednisolone (1-2 mg/ $\mathrm{kg}$ ) is recommended. After improvement, the dose should be reduced once every 1-2 weeks, and the reduction process should not be shorter than 4-6 weeks. For patients with grade 3 or 4 severe immunomyocarditis, ICI therapy should be stopped permanently, and intravenous high-dose methylprednisolone ( $1 \mathrm{~g} /$ day) pulse therapy is recommended for 3-5 days. After improvement, the dose should be reduced once every 1-2 weeks until a dose of $1-2 \mathrm{mg} / \mathrm{kg} / \mathrm{day}$, and the reduction process can last 6-8 weeks. $^{102}$ If the symptoms of patients with grade 3 or 4 immunomyocarditis are not relieved within 24 hours after taking large doses of corticosteroids, immunosuppressants such as antithymocyte globulin, infliximab or intravenous immunoglobulin should be considered, or treatment with the CTLA-4 agonist abatacept, to destroy peripheral immune cells and restore normal peripheral immune tolerance. ${ }^{103-107}$

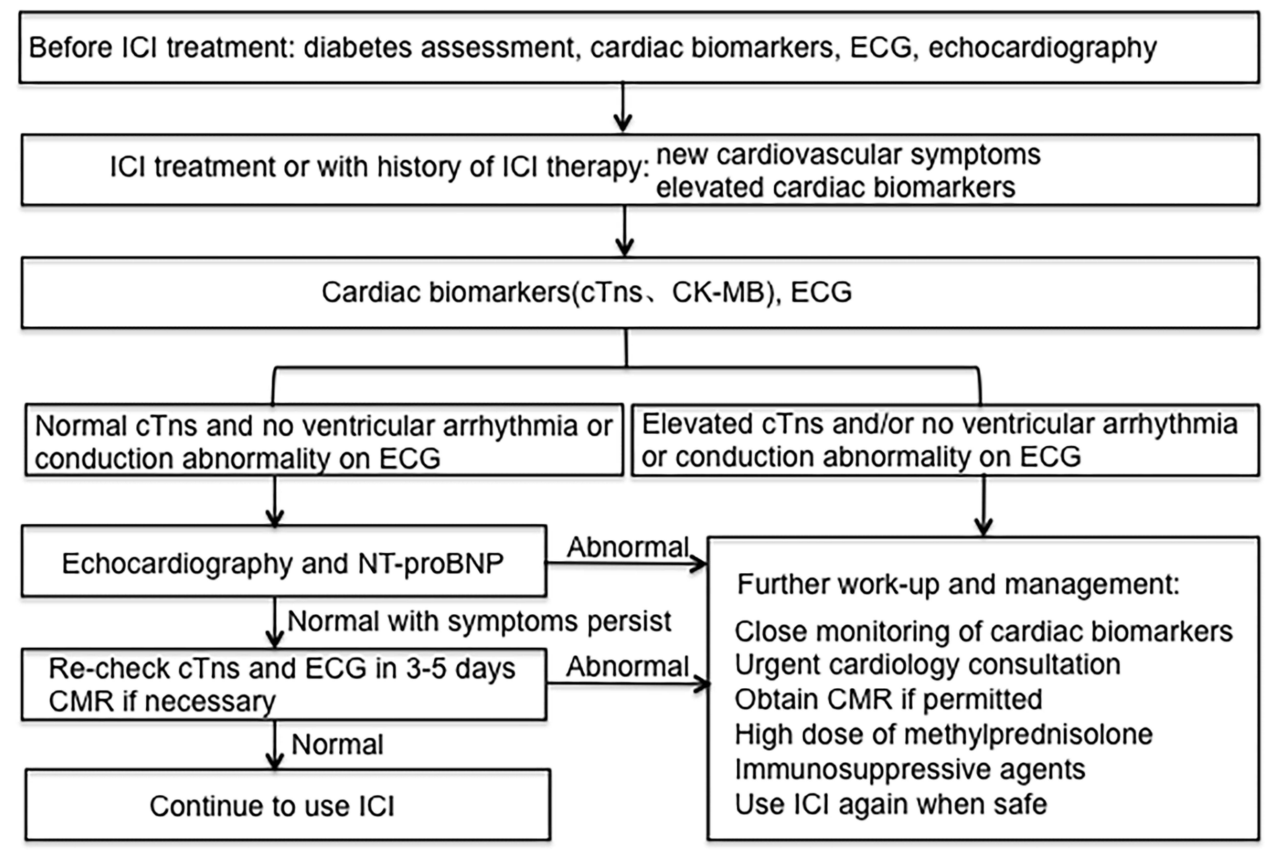

Figure 3 Proposed algorithm for work-up and management of $\mathrm{ICl}$-mediated myocarditis.

Abbreviations: ECG, electrocardiogram; cTns, cardiac troponins; CK-MB, creatine kinase isoenzyme-MB; CMR, cardiac magnetic resonance imaging; NT-proBNP, $\mathrm{N}$-terminal-pro-brain natriuretic peptide. 


\section{Challenges and Prospects}

\section{Differences in Tumour Immunogenicity}

At present, the FDA has approved ICIs as a first-line treatment or post-first-line treatment for patients with advanced cancer, including melanoma, NSCLC, renal cell carcinoma, Hodgkin's lymphoma, head and neck squamous cell carcinoma, urothelial carcinoma, colorectal cancer, hepatocellular carcinoma, gastric cancer, gastroesophageal junction adenocarcinoma, and Merkel cell carcinoma. According to reported studies, immunomyocarditis mostly occurs in patients with melanoma and non-small cell lung cancer, while cases of immunomyocarditis reported in other tumour types are relatively few. ${ }^{97}$ We speculated that the possible reason is that both melanoma and NSCLC are "immunogenic hot tumours". The clonal diversity of various antigenic molecules on the cell surface easily activates the $T$ cell response and increases the possibility of cross-immune reactions between tumour tissue and heart tissue, which leads to the occurrence of immunomyocarditis. In highly immunogenic tumours, ICI therapy is a double-edged sword that not only achieves a high response rate but also increases the possibility of immunomyocarditis. Therefore, when ICIs are used for patients with hyperimmunogenic tumours, a combination of cardioprotective agents may be a good choice.

\section{Immunotherapy Regimens}

In a retrospective study of immunomyocarditis data from 8 clinical centres, researchers found that the incidence of immunomyocarditis was higher in patients treated with antiPD-L1 than in those treated with anti-PD-1, while the incidence of immunomyocarditis was highest in patients treated with anti-CTLA-4. ${ }^{18}$ Another retrospective study included 42 cases of immunomyocarditis, of which the highest incidence was caused by anti-PD-1 treatment $(43 \%){ }^{14}$ Therefore, a study with a larger sample size is still needed to analyze which ICI is more likely to cause immunomyocarditis. At present, there is a general consensus that when anti-PD-1/PD-L1 and anti-CTLA-4 are used simultaneously, the incidence of immunomyocarditis is the highest, and the symptoms are more severe. ${ }^{84,102}$ Once severe immunomyocarditis occurs, the mortality rate of patients treated with ICIs is as high as $67 \%{ }^{97}$ Therefore, we need to constantly explore the efficacy of new ICIs or activators in cancer treatment, and we expect to achieve lower toxicity and side effects. ${ }^{85}$

\section{Candidate Biomarkers}

As important cardiac biomarkers, troponin and natriuretic peptide play a critical role in the diagnosis of conventional heart disease. ${ }^{108}$ It has been reported that the expression of troponin is significantly increased in patients with immunomyocarditis. Because patients often also have myositis, additional monitoring of creatine kinase, myoglobin and lactate dehydrogenase is necessary. ${ }^{109}$ In addition, Tsuruda et al monitored the changes in serum concentrations of IL6, IL-8 and GM-CSF in 3 patients with immunomyocarditis at different stages of the disease. They found that IL-8 levels were significantly increased in 3 patients with immunomyocarditis, suggesting that IL-8 may be related to the severity of immunomyocarditis. However, this result still needs to be further verified by a large clinical trial. ${ }^{110}$ To date, there is still a lack of research on biomarkers for the early prediction of immunomyocarditis. ${ }^{111} \mathrm{We}$ need large-scale clinical studies to explore effective biomarkers that can predict immunomyocarditis early to maximize the killing of tumour cells on the basis of the safe use of ICIs.

\section{Conclusions}

Immunomyocarditis is a special immunotherapy-mediated toxicity of autoimmune T cells activated by ICIs that enables the myocardium to overcome peripheral immune tolerance through a series of immune activation effects and inflammatory cytokines. The clinical characteristics of immunomyocarditis are different from those caused by common myocarditis and cytotoxic drugs. Immunomyocarditis usually occurs within 6 weeks after initial treatment with ICIs. The course of the disease progresses rapidly, and the clinical symptoms are serious. In the course of treatment, high-dose methylprednisolone pulse therapy is necessary. However, due to the low incidence of immunomyocarditis, there is still a lack of clinical research on its pathogenesis and the use of biomarkers to predict its occurrence. With the wide use of ICIs and the high mortality of immunomyocarditis, large-scale clinical studies on early predictive biomarkers in immunomyocarditis are needed.

\section{Abbreviations}

ICI, Immune checkpoint inhibitor; PD-1, programmed death1; PD-L1, programmed death-ligand 1; Treg, regulatory T cell; MDSC, myeloid-derived suppressor cell; CTLA-4, cytotoxic $\mathrm{T}$ lymphocyte-associated antigen-4; TIM-3, T cell immunoglobulin domain and mucin domain-3; LAG-3, Lymphocyte activation gene-3; TCR, T cell receptor; 
TIGIT, T cell immunoreceptor with Ig and ITIM domains; NSCLC, Non-small cell lung cancer.

\section{Author Contributions}

All authors made substantial contributions to conception and design, acquisition of data, or analysis and interpretation of data; took part in drafting the article or revising it critically for important intellectual content; agreed to submit to the current journal; gave final approval of the version to be published; and agree to be accountable for all aspects of the work.

\section{Disclosure}

The authors report no conflicts of interest in this work.

\section{References}

1. Baumeister SH, Freeman GJ, Dranoff G, Sharpe AH. Coinhibitory pathways in immunotherapy for cancer. Annu Rev Immunol. 2016;34:539-573. doi:10.1146/annurev-immunol-032414-112049

2. Ribas A, Wolchok JD. Cancer immunotherapy using checkpoint blockade. Science. 2018;359:1350-1355. doi:10.1126/science. aar4060

3. Clarke JM, George DJ, Lisi S, Salama AKS. Immune checkpoint blockade: the new frontier in cancer treatment. Target Oncol. 2018;13(1):1-20. doi:10.1007/s11523-017-0549-7

4. Gong J, Chehrazi-Raffle A, Reddi S, Salgia R. Development of PD-1 and PD-L1 inhibitors as a form of cancer immunotherapy: a comprehensive review of registration trials and future considerations. J Immunother Cancer. 2018;6(1):8. doi:10.1186/ s40425-018-0316-z

5. Rittmeyer A, Barlesi F, Waterkamp D, et al. Atezolizumab versus docetaxel in patients with previously treated non-small-cell lung cancer (OAK): a phase 3, open-label, multicentre randomised controlled trial. Lancet. 2017;389(10066):255-265. doi:10.1016/ S0140-6736(16)32517-X

6. Horn L, Spigel DR, Vokes EE, et al. Nivolumab versus docetaxel in previously treated patients with advanced non-small-cell lung cancer: two-year outcomes from two randomized, open-label, phase III trials (CheckMate 017 and CheckMate 057). J Clin Oncol. 2017;35(35):3924-3933. doi:10.1200/JCO.2017.74.3062

7. KEYNOTE-042 Investigators; Mok TSK, Wu YL, Kudaba I, et al. Pembrolizumab versus chemotherapy for previously untreated, PD-L1-expressing, locally advanced or metastatic non-small-cell lung cancer (KEYNOTE-042): a randomised, open-label, controlled, phase 3 trial. Lancet. 2019;393 (10183):1819-1830. doi:10.1016/S0140-6736(18)32409-7.

8. Reck M, Rodríguez-Abreu D, Robinson AG, et al. Updated analysis of KEYNOTE-024: pembrolizumab versus platinum-based chemotherapy for advanced non-small-cell lung cancer with PD-L1 tumor proportion score of $50 \%$ or greater. J Clin Oncol. 2019;37(7):537-546. doi:10.1200/JCO.18.00149

9. Remon J, Besse B, Soria JC. Successes and failures: what did we learn from recent first-line treatment immunotherapy trials in non-small cell lung cancer? BMC Med. 2017;15(1):55. doi:10.1186/s12916-017-0819-3

10. Dang TO, Ogunniyi A, Barbee MS, Drilon A. Pembrolizumab for the treatment of PD-L1 positive advanced or metastatic non-small cell lung cancer. Expert Rev Anticancer Ther. 2016;16(1):13-20. doi:10.1586/14737140.2016.1123626
11. Weber JS, D'Angelo SP, Minor D, et al. Nivolumab versus chemotherapy in patients with advanced melanoma who progressed after anti-CTLA-4 treatment (CheckMate 037): a randomised, controlled, open-label, phase 3 trial. Lancet Oncol. 2015;16(4):375-384. doi:10.1016/S1470-2045(15)700 76-8

12. Wang DY, Salem JE, Cohen JV, et al. Fatal toxic effects associated with immune checkpoint inhibitors: a systematic review and meta-analysis. JAMA Oncol. 2018;4(12):1721-1728. doi:10.1001/jamaoncol.2018.3923

13. Friedman CF, Proverbs-Singh TA, Postow MA. Treatment of the immune-related adverse effects of immune checkpoint inhibitors: a review. JAMA Oncol. 2016;2(10):1346-1353. doi:10.1001/ jamaoncol.2016.1051

14. Atallah-Yunes SA, Kadado AJ, Kaufman GP, HernandezMontfort J. Immune checkpoint inhibitor therapy and myocarditis: a systematic review of reported cases. J Cancer Res Clin Oncol. 2019;145(6):1527-1557. doi:10.1007/s00432-019-029 27-x

15. Ganatra S, Neilan TG. Immune checkpoint inhibitor- associated myocarditis. Oncologist. 2018;23:879-886. doi:10.1634/theoncologist.2018-0130

16. Johnson DB, Balko JM, Compton ML, et al. Fulminant myocarditis with combination immune checkpoint blockade. $N$ Engl J Med. 2016;375:1749-1755. doi:10.1056/NEJMoa 1609214

17. Ederhy S, Voisin AL, Champiat S. Myocarditis with immune check- point blockade. N Engl J Med. 2017;376(3):290-291.

18. Escudier M, Cautela J, Malissen N, et al. Clinical features, management, and outcomes of immune checkpoint inhibitor-related cardiotoxicity. Circulation. 2017;136(21):2085-2087. doi:10.11 61/CIRCULATIONAHA.117.030571

19. McDowall LM, Fernando SL, Ange N, Yun J, Chia KKM. Immune checkpoint inhibitor-mediated myocarditis and ventricular tachycardia storm. Heart Rhythm Case Rep. 2019;5 (10):497-500. doi:10.1016/j.hrcr.2019.06.006

20. National Comprehensive Cancer Network; Brahmer JR, Lacchetti C, Schneider BJ, et al. Management of immune-related adverse events in patients treated with immune checkpoint inhibitor therapy: american society of clinical oncology clinical practice guideline. J Clin Oncol. 2018;36 (17):1714-1768. doi:10.1200/JCO.2017.77.6385.

21. Altan M, Toki MI, Gettinger SN, et al. Immune checkpoint inhibitor-associated pericarditis. J Thorac Oncol. 2019;14 (6):1102-1108. doi:10.1016/j.jtho.2019.02.026

22. Chambers CA, Kuhns MS, Egen JG, Allison JP. CTLA4-mediated inhibition in regulation of $\mathrm{T}$ cell responses: mechanisms and manipulation in tumor immunotherapy. Annu Rev Immunol. 2001;19:565-594. doi:10.1146/annurev.immunol.19. 1.565

23. Walunas TL, Lenschow DJ, Bakker CY, et al. CTLA-4 can function as a negative regulator of T cell activation. Immunity. 1994;1 (5):405-413. doi:10.1016/1074-7613(94)90071-X

24. Nishimura H, Nose M, Hiai H, Minato N, Honjo T. Development of lupus-like autoimmune diseases by disruption of the PD-1 gene encoding an ITIM motif-carrying immunoreceptor. Immunity. 1999;11(2):141-151

25. Tivol EA, Borriello F, Schweitzer AN, Lynch WP, Bluestone JA, Sharpe AH. Loss of CTLA-4 leads to massive lymphoproliferation and fatal multiorgan tissue destruction, revealing a critical negative regulatory role of CTLA-4. Immunity. 1995;3 (5):541-547. doi:10.1016/1074-7613(95)90125-6

26. Waterhouse $\mathrm{P}$, Penninger JM, Timms E, et al. Lymphoproliferative disorders with early lethality in mice deficient in Ctla-4. Science. 1995;270(5238):985-988. doi:10.1126/ science. 270.5238 .985 
27. Katsuya Y, Fujita Y, Horinouchi H, Ohe Y, Watanabe S, Tsuta K. Immunohistochemical status of PD-L1 in thymoma and thymic carcinoma. Lung Cancer. 2015;88(2):154-159. doi:10.1016/j. lungcan.2015.03.003

28. Fay AP, Signoretti S, Callea M, et al. Programmed death ligand-1 expression in adrenocortical carcinoma: an exploratory biomarker study. J Immunother Cancer. 2015;3:3. doi:10.1186/s40425-0150047-3

29. Jacobs JF, Idema AJ, Bol KF, et al. Regulatory $\mathrm{T}$ cells and the PD-L1/PD-1 pathway mediate immune suppression in malignant human brain tumors. Neuro Oncol. 2009;11(4):394-402. doi:10.1215/15228517-2008-104

30. Hodi FS, Chesney J, Pavlick AC, et al. Combined nivolumab and ipilimumab versus ipilimumab alone in patients with advanced melanoma: 2-year overall survival outcomes in a multicentre, randomised, controlled, Phase 2 trial. Lancet Oncol. 2016;17 (11):1558-1568. doi:10.1016/S1470-2045(16)30366-7

31. Taube JM, Klein A, Brahmer JR, et al. Association of PD-1, PD-1 ligands, and other features of the tumor immune microenvironment with response to anti-PD-1 therapy. Clin Cancer Res. 2014;20:5064-5074. doi:10.1158/1078-0432.CCR-13-3271

32. Topalian SL, Hodi FS, Brahmer JR, et al. Safety, activity, and immune correlates of anti-PD-1 antibody in cancer. $N$ Engl $J$ Med. 2012;366:2443-2454. doi:10.1056/NEJMoa1200690

33. Gettinger S, Herbst RS. B7-h1/pd-1 blockade therapy in non-small cell lung cancer: current status and future direction. Cancer J. 2014;20(4):281-289. doi:10.1097/PPO.0000000000 000063

34. Meng X, Liu Y, Zhang J, Teng F, Xing L, Yu J. PD-1/PD-L1 checkpoint blockades in non-small cell lung cancer: new development and challenges. Cancer Lett. 2017;405:29-37. doi:10.1016/j.canlet.2017.06.033

35. Dai S, Jia R, Zhang X, Fang Q, Huang L. The PD-1/PD-Ls pathway and autoimmune diseases. Cell Immunol. 2014;290 (1):72-79. doi:10.1016/j.cellimm.2014.05.006

36. Victor TS, Rech AJ, Maity A, et al. Radiation and dual checkpoint blockade activates non-redundant immune mechanisms in cancer. Nature. 2015;520:7547.

37. Eggermont AM, Chiarion-Sileni V, Grob JJ, et al. Adjuvant ipilimumab versus placebo after complete resection of high-risk stage III melanoma (EORTC 18071): a randomised, double-blind, phase 3 trial. Lancet Oncol. 2015;16(5):522-530. doi:10.1016/ S1470-2045(15)70122-1

38. Maio M, Scherpereel A, Calabrò $\mathrm{L}$, et al. Tremelimumab as second-line or third-line treatment in relapsed malignant mesothelioma (DETERMINE): a multicentre, international, randomised, double-blind, placebo-controlled phase $2 \mathrm{~b}$ trial. Lancet Oncol. 2017;18(9):1261-1273. doi:10.1016/S1470-2045(17)30446-1

39. Schachter J, Ribas A, Long GV, et al. Pembrolizumab versus ipilimumab for advanced melanoma: finaloverall survival results of a multicentre, randomised, open-label phase 3 study (KEYNOTE-006). Lancet. 2017;390(10105):1853-1862. doi:10. 1016/S0140-6736(17)31601-X

40. Wakuda K, Yabe M, Kodama H, et al. Efficacy of pembrolizumab in patients with brain metastasis caused by previously untreated non-small cell lung cancer with high tumor PD-L1 expression. Lung Cancer. 2021;151:60-68. doi:10.1016/j.lungcan.2020.11. 009

41. KEYNOTE-024 Investigators; Reck M, Rodríguez-Abreu D, Robinson AG, et al. Pembrolizumab versus chemotherapy for PD-L1-positive non-small-cell lung cancer. $N$ Engl $J$ Med. 2016;375(19):1823-1833. doi:10.1056/NEJMoa1606774.

42. Maubec E, Boubaya M, Petrow P, et al. Phase II study of pembrolizumab as first-line, single-drug therapy for patients with unresectable cutaneous squamous cell carcinomas. J Clin Oncol. 2020;38(26):3051-3061. doi:10.1200/JCO.19.03357
43. Brahmer J, Reckamp KL, Baas P, et al. Nivolumab versus docetaxel in advanced squamous-cell non-small-cell lung cancer. $N$ Engl J Med. 2015;373(2):123-135. doi:10.1056/NEJMoa 1504627

44. Borghaei H, Paz-Ares L, Horn L, et al. Nivolumab versus docetaxel in advanced non squamous non-small-cell lung cancer. $N$ Engl J Med. 2015;373(17):1627-1639. doi:10.1056/NEJMoa 1507643

45. Rexer H, Steiner T, Grünwald V. First-line therapy in advanced renal cell carcinoma: a randomized phase II study to examine early switch of tyrosine kinase inhibitors to nivolumab compared to continued tyrosine kinase inhibitor therapy in patients with advanced or metastatic renal cell carcinoma and stable disease after three months of treatment (NIVOSWITCH)-AN 38/15 of the AUO. Urologe A. 2017;56(4):509-511.

46. Younes A, Santoro A, Shipp M, et al. Nivolumab for classical Hodgkin's lymphoma after failure of both autologous stem-cell transplantation and brentuximab vedotin: a multicentre, multicohort, single-arm phase 2 trial. Lancet Oncol. 2016;17 (9):1283-1294. doi:10.1016/S1470-2045(16)30167-X

47. Ferris RL, Licitra L, Fayette J, et al. Nivolumab in patients with recurrent or metastatic squamous cell carcinoma of the head and neck: efficacy and safety in CheckMate 141 by prior cetuximab use. Clin Cancer Res. 2019;25(17):5221-5230. doi:10.1158/ 1078-0432.CCR-18-3944

48. Sharma P, Retz M, Siefker-Radtke A, et al. Nivolumab in metastatic urothelial carcinoma after platinum therapy (CheckMate 275): a multicentre, single-arm, phase 2 trial. Lancet Oncol. 2017;18(3):312-322. doi:10.1016/S1470-2045(17)30065-7

49. El-Khoueiry AB, Sangro B, Yau T, et al. Nivolumab in patients with advanced hepatocellular carcinoma (CheckMate 040): an open-label, non-comparative, Phase $1 / 2$ dose escalation and expansion trial. Lancet. 2017;389(10088):2492-2502. doi:10. 1016/S0140-6736(17)31046-2

50. Snyder A, Nathanson T, Funt SA, et al. Contribution of systemic and somatic factors to clinical response and resistance to PD-L1 blockade in urothelial cancer: an exploratory multi-omic analysis. PLoS Med. 2017;14(5):e1002309. doi:10.1371/journal.pmed.10 02309

51. Fehrenbacher L, Spira A, Ballinger M, et al. Atezolizumab versus docetaxel for patients with previously treated non-small-cell lung cancer (POPLAR): a multicentre, open-label, phase 2 randomised controlled trial. Lancet. 2016;387(10030):1837-1846. doi:10.10 16/S0140-6736(16)00587-0

52. Chalabi M, Cardona A, Nagarkar DR, et al. Efficacy of chemotherapy and atezolizumab in patients with non-small-cell lung cancer receiving antibiotics and proton pump inhibitors: pooled post hoc analyses of the OAK and POPLAR trials. Ann Oncol. 2020;31(4):525-531. doi:10.1016/j.annonc.2020.01.006

53. Powles T, O'Donnell PH, Massard C, et al. Efficacy and safety of durvalumab in locally advanced or metastatic urothelial carcinoma: updated results from a phase $1 / 2$ open-label study. JAMA Oncol. 2017;3(9):e172411. doi:10.1001/jamaoncol.2017.2411

54. Hui R, Özgüroğlu M, Villegas A, et al. Patient-reported outcomes with durvalumab after chemoradiotherapy in stage III, unresectable non-small-cell lung cancer (PACIFIC): a randomised, controlled, phase 3 study. Lancet Oncol. 2019;20(12):1670-1680. doi:10.1016/S1470-2045(19)30519-4

55. Goldman JW, Dvorkin M, Chen Y, et al. Durvalumab, with or without tremelimumab, plus platinum-etoposide versus platinum-etoposide alone in first-line treatment of extensive-stage small-cell lung cancer (CASPIAN): updated results from a randomised, controlled, open-label, phase 3 trial. Lancet Oncol. 2021;22(1):51-65. doi:10.1016/S1470-2045(20) 30539-8 
56. Kaufman HL, Russell J, Hamid O, et al. Avelumab in patients with chemotherapy-refractory metastatic Merkel cell carcinoma: a multicentre, single-group, open-label, phase 2 trial. Lancet Oncol. 2016;17(10):1374-1385. doi:10.1016/S1470-2045(16)30364-3

57. Patel MR, Ellerton J, Infante JR, et al. Avelumab in metastatic urothelial carcinoma after platinum failure (JAVELIN Solid Tumor): pooled results from two expansion cohorts of an open-label, phase 1 trial. Lancet Oncol. 2018;19(1):51-64. doi:10.1016/S1470-2045(17)30900-2

58. Gubens MA, Sequist LV, Stevenson JP, et al. Pembrolizumab in combination with ipilimumab as second-line or later therapy for advanced non-small-cell lung cancer: KEYNOTE-021 cohorts $D$ and H. Lung Cancer. 2019;130:59-66. doi:10.1016/j. lungcan.2018.12.015

59. Scherpereel A, Mazieres J, Greillier L, et al. Nivolumab or nivolumab plus ipilimumab in patients with relapsed malignant pleural mesothelioma (IFCT-1501 MAPS2): a multicentre, open-label, randomised, non-comparative, phase 2 trial. Lancet Oncol. 2019;20 (2):239-253. doi:10.1016/S1470-2045(18)30765-4

60. Robert C, Long GV, Brady B, et al. Nivolumab in previously untreated melanoma without BRAF mutation. $N$ Engl J Med. 2015;372(4):320-330. doi:10.1056/NEJMoa1412082

61. Han S, Feng S, Xu L, et al. Tim-3 on peripheral CD4+ and CD8+ T cells is involved in the development of glioma. DNA Cell Biol. 2014;33(4):245-250. doi:10.1089/dna.2013.2306

62. Liu Z, Han H, He X, et al. Expression of the galectin-9-Tim-3 pathway in glioma tissues is associated with the clinical manifestations of glioma. Oncol Lett. 2016;11(3):1829-1834. doi:10. 3892/ol.2016.4142

63. Li G, Wang Z, Zhang C, et al. Molecular and clinical characterization of TIM- 3 in glioma through 1024 samples. Oncoimmunology. 2017;6(8):e1328339. doi:10.1080/2162402X. 2017.1328339

64. Sakuishi K, Apetoh L, Sullivan JM, Blazar BR, Kuchroo VK, Anderson AC. Targeting Tim-3 and PD-1 pathways to reverse $\mathrm{T}$ cell exhaustion and restore anti-tumor immunity. $J$ Exp Med. 2010;207:2187-2194. doi:10.1084/jem.20100643

65. Granier C, De Guillebon ED, Blanc C, et al. Mechanisms of action and rationale for the use of checkpoint inhibitors in cancer. ESMO Open. 2017;2(2):e000213. doi:10.1136/esmoopen-2017-000213

66. Matsuzaki J, Gnjatic S, Mhawech-Fauceglia P, et al. Tumorinfiltrating NY-ESO-1-specific CD8+ T cells are negatively regulated by LAG-3 and PD-1 in human ovarian cancer. Proc Natl Acad Sci U S A. 2010;107(17):7875-7880. doi:10.1073/ pnas. 1003345107

67. Woo SR, Turnis ME, Goldberg MV, et al. Immune inhibitory molecules LAG-3 and PD-1 synergistically regulate T-cell function to promote tumoral immune escape. Cancer Res. 2012;72 (4):917-927. doi:10.1158/0008-5472.CAN-11-1620

68. Johnston RJ, Comps-Agrar L, Hackney J, et al. The immunoreceptor TIGIT regulates antitumor and antiviral CD8(+) $\mathrm{T}$ cell effector function. Cancer Cell. 2014;26(6):923-937. doi:10.1016/ j.ccell.2014.10.018

69. Nishimura $\mathrm{H}$, Minato $\mathrm{N}$, Nakano $\mathrm{T}$, Honjo $\mathrm{T}$. Immunological studies on PD-1 deficient mice: implication of PD-1 as a negative regulator for $\mathrm{B}$ cell responses. Int Immunol. 1998;10:1563-1572. doi:10.1093/intimm/10.10.1563

70. Freeman GJ, Long AJ, Iwai Y, et al. Engagement of the PD-1 immunoinhibitory receptor by a novel B7 family member leads to negative regulation of lymphocyte activation. $J$ Exp Med. 2000;192(7):1027-1034. doi:10.1084/jem.192.7.1027

71. Shindo Y, Yoshimura K, Kuramasu A, et al. Combination immunotherapy with 4-1BB activation and PD-1 blockade enhances antitumor efficacy in a mouse model of subcutaneous tumor. Anticancer Res. 2015;35(1):129-136.
72. Rodig N, Ryan T, Allen JA, et al. Endothelial expression of PD-L1 and PD-L2 down- regulates CD8+ T cell activation and cytolysis. Eur J Immunol. 2003;33:3117-3126. doi:10.1002/ eji.200324270

73. Grabie N, Gotsman I, DaCosta R, et al. Endothelial programmed death-1 ligand 1 (PD-L1) regulates CD8+ T-cell mediated injury in the heart. Circulation. 2007;116(18):2062-2071. doi:10.1161/ CIRCULATIONAHA.107.709360

74. Lichtman AH. The heart of the matter: protection of the myocardium from T cells. J Autoimmun. 2013;45:90-96. doi:10.1016/j. jaut.2013.05.004

75. Grabie N, Lichtman AH, Padera R. T cell checkpoint regulators in the heart. Cardiovasc Res. 2019.

76. Nishimura H, Okazaki T, Tanaka Y, et al. Autoimmune dilated cardiomyopathy in PD-1 receptor-deficient mice. Science. 2001;291:319-322. doi:10.1126/science.291.5502.319

77. Tarrio ML, Grabie N, Bu DX, Sharpe AH, Lichtman AH. PD-1 protects against inflammation and myocyte damage in $\mathrm{T}$ cell-mediated myocarditis. J Immunol. 2012;188(10):4876-4884. doi:10.4049/jimmunol.1200389

78. Wang J, Okazaki IM, Yoshida T, et al. PD-1 deficiency results in the development of fatal myocarditis in MRL mice. Int Immunol. 2010;22(6):443-452. doi:10.1093/intimm/dxq026

79. Eppihimer MJ, Gunn J, Freeman GJ, et al. Expression and regulation of the PD-L1 immunoinhibitory molecule on microvascular endothelial cells. Microcirculation. 2002;9:133-145. doi:10. 1080/713774061

80. Stanciu LA, Bellettato CM, Laza-Stanca V, Coyle AJ, Papi A, Johnston SL. Expression of programmed death-1 ligand (PD-L) 1, PD-L2, B7-H3, and inducible costimulator ligand on human respiratory tract epithelial cells and regulation by respiratory syncytial virus and type 1 and 2 cytokines. $J$ Infect Dis. 2006;193:404-412. doi:10.1086/499275

81. Ding $\mathrm{H}, \mathrm{Wu} \mathrm{X}, \mathrm{Gao} \mathrm{W}$. PD-L1 is expressed by human renal tubular epithelial cells and suppresses T cell cytokine synthesis. Clin Immunol. 2005;115:184-191. doi:10.1016/j.clim.2005.01.005

82. Keir ME, Liang SC, Guleria I, et al. Tissue expression of PD-L1 mediates peripheral $\mathrm{T}$ cell tolerance. J Exp Med. 2006; 203:883-895. doi:10.1084/jem.20051776

83. Krishna S, Perazella MA, Shirali AC. Cardiorenal complications of immune checkpoint inhibitors. Nat Rev Nephrol. 2018.

84. Salem JE, Manouchehri A, Moey M, et al. Cardiovascular toxicities associated with immune checkpoint inhibitors: an observational, retrospective, pharmacovigilance study. Lancet Oncol. 2018;19(12):1579-1589. doi:10.1016/S1470-2045(18)30608-9

85. Anderson AC, Joller N, Kuchroo VK. Lag-3, Tim-3, and TIGIT: co-inhibitory receptors with specialized functions in immune regulation. Immunity. 2016;44(5):989-1004. doi:10.1016/j. immuni.2016.05.001

86. Yamaguchi K, Mishima K, Ohmura H, et al. Activation of central/ effector memory $\mathrm{T}$ cells and $\mathrm{T}$-helper 1 polarization in malignant melanoma patients treated with anti-programmed death-1 antibody. Cancer Sci. 2018;109(10):3032-3042. doi:10.1111/cas.13758

87. Meng X, Yang J, Dong M, et al. Regulatory T cells in cardiovascular diseases. Nat Rev Cardiol. 2016;13:167-179. doi:10.1038/ nrcardio.2015.169

88. Walker JA, McKenzie A. TH2 cell development and function. Nat Rev Immunol. 2018;18(2):121-133. doi:10.1038/nri.2017.118

89. Eriksson U, Kurrer MO, Sebald W, Brombacher F, Kopf M. Dual role of the IL-12/IFN-gamma axis in the development of autoimmune myocarditis: induction by IL-12 and protection by IFNgamma. J Immunol. 2001;167:5464-5469. doi:10.4049/ jimmunol.167.9.5464

90. Golstein P, Griffiths GM. An early history of T cell-mediated cytotoxicity. Nat Rev Immunol. 2018;18:527-535. doi:10.1038/ s41577-018-0009-3 
91. Massilamany C, Gangaplara A, Basavalingappa RH, et al. Localization of CD8 $\mathrm{T}$ cell epitope within cardiac myosin heavy chain-alpha334-352 that induces autoimmune myocarditis in $\mathrm{a} / \mathrm{J}$ mice. Int $J$ Cardiol. 2016;202:311-321. doi:10.1016/j.ijcard.20 15.09 .016

92. Reuben A, Petaccia de Macedo M, McQuade J, et al. Comparative immunologic characterization of autoimmune giant cell myocarditis with ipilimumab. Oncoimmunology. 2017;6(12): e1361097. doi:10.1080/2162402X.2017.1361097

93. Hardy T, Yin M, Chavez JA, et al. Acute fatal myocarditis after a single dose of anti-PD-1 immunotherapy, autopsy findings: a case report. Cardiovasc Pathol. 2020;46:107202. doi:10.1016/ j.carpath.2020.107202

94. Tadokoro T, Keshino E, Makiyama A, et al. Acute lymphocytic myocarditis with anti-PD-1 antibody nivolumab. Circ Heart Fail. 2016;9(10):e003514.

95. Sobol I, Chen CL, Mahmood SS, Borczuk AC. Histopathologic characterization of myocarditis associated with immune checkpoint inhibitor therapy. Arch Pathol Lab Med. 2020;144 (11):1392-1396. doi:10.5858/arpa.2019-0447-OA

96. Champion SN, Stone JR. Immune checkpoint inhibitor associated myocarditis occurs in both high-grade and low-grade forms. Mod Pathol. 2020;33(1):99-108. doi:10.1038/s41379-019-0363-0

97. Moslehi JJ, Salem JE, Sosman JA, Lebrun-Vignes B, Johnson DB. Increased reporting of fatal immune checkpoint inhibitor-associated myocarditis. Lancet. 2018;391(10124):933. doi:10.1016/S0140-6736(18)30533-6

98. Dolladille C, Ederhy S, Allouche S, et al. Late cardiac adverse events in patients with cancer treated with immune checkpoint inhibitors. J Immunother Cancer. 2020;8(1):e000261. doi:10.11 36/jitc-2019-000261

99. Herbst RS, Baas P, Kim DW, et al. Pembrolizumab versus docetaxel for previously treated, PD-L1-positive, advanced non-small-cell lung cancer (KEYNOTE-010): a randomised controlled trial. Lancet. 2016;387:1540-1550. doi:10.1016/S01406736(15)01281-7

100. Zimmer L, Goldinger SM, Hofmann L, et al. Neurological, respiratory, musculoskeletal, cardiac and ocular side-effects of anti-PD-1 therapy. Eur J Cancer. 2016;60:210-225. doi:10. 1016/j.ejca.2016.02.024

101. Thompson JA, Schneider BJ, Brahmer J, et al. NCCN guidelines insights: management of immunotherapy-related toxicities, version 1.2020. J Natl Compr Canc Netw. 2020;18(3):230-241. doi:10.6004/jnccn.2020.0012

102. Mahmood SS, Fradley MG, Cohen JV, et al. Myocarditis in patients treated with immune checkpoint inhibitors. $\mathrm{J} \mathrm{Am} \mathrm{Coll}$ Cardiol. 2018;71(16):1755-1764. doi:10.1016/j.jacc.2018.02.037
103. Agrawal N, Khunger A, Vachhani P, et al. Cardiac toxicity associated with immune checkpoint inhibitors: case series and review of the literature. Case Rep Oncol. 2019;12(1):260-276. doi:10. 1159/000498985

104. Jain V, Bahia J, Mohebtash M, Barac A. Cardiovascular complications associated with novel cancer immunotherapies. Curr Treat Options Cardiovasc Med. 2017;19(5):36. doi:10.1007/s11936017-0532-8

105. Kobashigawa J, Crespo-Leiro MG, Ensminger SM, et al. Consensus conference participants. Report from a consensus conference on antibody-mediated rejection in heart transplantation. $J$ Heart Lung Transplant. 2011;30(3):252-269. doi:10.1016/j. healun.2010.11.003

106. Rodriguez ER, Skojec DV, Tan CD, et al. Antibody-mediated rejection in human cardiac allografts: evaluation of immunoglobulins and complement activation products $\mathrm{C} 4 \mathrm{~d}$ and $\mathrm{C} 3 \mathrm{~d}$ as markers. Am J Transplant. 2005;5(11):2778-2785. doi:10.1111/ j.1600-6143.2005.01074.X

107. Salem JE, Allenbach Y, Vozy A, et al. Abatacept for severe immune checkpoint inhibitor-associated myocarditis. $N$ Engl J Med. 2019;380(24):2377-2379. doi:10.1056/NEJMc1901677

108. Ponikowski P, Voors AA, Anker SD, et al. 2016 ESC guidelines for the diagnosis and treatment of acute and chronic heart failure: the Task Force for the diagnosis and treatment of acute and chronic heart failure of the European Society of Cardiology (ESC)Developed with the special contribution of the Heart Failure Association (HFA) of the ESC. Eur Heart J. 2016;37 (27):2129-2200. doi:10.1093/eurheartj/ehw128

109. Committee for Clinical Cardiovascular Medicine of the German Cardiac Society; Rassaf T, Totzeck M, Backs J, et al. Oncocardiology: consensus paper of the German Cardiac Society, the German Society for Pediatric Cardiology and Congenital Heart Defects and the German Society for Hematology and Medical Oncology. Clin Res Cardiol. 2020;109(10):1197-1222. doi:10. 1007/s00392-020-01636-7.

110. Tsuruda T, Yoshikawa N, Kai M, et al. The cytokine expression in patients with cardiac complication after immune checkpoint inhibitor therapy. Intern Med. 2021;60(3):423-429. doi:10.2169/internalmedicine.5317-20

111. Nakamura Y. Biomarkers for immune checkpoint inhibitor-mediated tumor response and adverse events. Front Med (Lausanne). 2019;6:119. doi:10.3389/fmed.2019.00119
Journal of Inflammation Research

\section{Publish your work in this journal}

The Journal of Inflammation Research is an international, peerreviewed open-access journal that welcomes laboratory and clinical findings on the molecular basis, cell biology and pharmacology of inflammation including original research, reviews, symposium reports, hypothesis formation and commentaries on: acute/chronic inflammation; mediators of inflammation; cellular processes; molecular mechanisms; pharmacology and novel anti-inflammatory drugs; clinical conditions involving inflammation. The manuscript management system is completely online and includes a very quick and fair peerreview system. Visit http://www.dovepress.com/testimonials.php to read real quotes from published authors. 